\title{
New Parameter Proposed for Industrial Acceptance Measurements of Rolling Bearings
}

\section{Stanisław Adamczak}

Kielce University of Technology: Politechnika Swietokrzyska

Ryszard Domagalski

Kielce University of Technology: Politechnika Swietokrzyska

Mateusz Wrzochal ( $\square$ wrzochalm@gmail.com)

Kielce University of Technology: Politechnika Swietokrzyska

Grzegorz Piotrowicz

Kielce University of Technology: Politechnika Swietokrzyska

Sylwester Wnuk

Kielce University of Technology: Politechnika Swietokrzyska

\section{Research Article}

Keywords: rolling bearings, frictional moment, industrial measurement, quality control

Posted Date: October 25th, 2021

DOI: https://doi.org/10.21203/rs.3.rs-974400/v1

License: (c) (1) This work is licensed under a Creative Commons Attribution 4.0 International License. Read Full License 


\title{
NEW PARAMETER PROPOSED FOR INDUSTRIAL ACCEPTANCE MEASUREMENTS OF ROLLING BEARINGS
}

\author{
Stanisław Adamczak ${ }^{1}$, Ryszard Domagalski ${ }^{1}$, Mateusz Wrzochal ${ }^{1}$, \\ Grzegorz Piotrowicz ${ }^{2}$, Sylwester Wnuk ${ }^{2}$ \\ ${ }^{1}$ Kielce University of Technology, Faculty of Mechatronics and Mechanical Engineering, \\ al. Tysiąclecia Państwa Polskiego 7, 25-314 Kielce,Poland (adamczak@tu.kielce.pl,rdomagalski@tu.kielce.pl, \\ mwrzochal@tu.kielce.pl) \\ ${ }^{2}$ Fabryka Łożysk Tocznych - Kraśnik S.A. (Polish Bearings Factory), Fabryczna 6, 23-204 Kraśnik, Poland \\ (gpiotrowicz@flt.krasnik.pl,swnuk@flt.krasnik.pl)
}

\begin{abstract}
The frictional moment, together with vibrations and durability, is one of the most important parameters determining the quality of bearings and their suitability for the intended applications. The frictional moment value allows for obtaining essential information about the bearing, both in terms of its structure, the quality of mating elements, cleanliness and the specific qualities of the lubricant used. Since bearings are commonly used in the automotive industry, machine industry and household appliances, the need to reduce friction in rolling bearings is critical to increase the bearing efficiency, reduce energy consumption and protect the environment. The article presents a new industrial device for testing the bearing frictional moment of rolling bearings at the stage of their production. The device is characterized by an innovative design that allows for testing a wide range of bearing dimensions, applying significant axial loads, additional measurement of the mounting width of the bearings, and most importantly, testing the cone bearings. This article presents the general assumptions and the mechanical design of the new device for measuring the frictional moment of rolling bearings, as well as the verification of the device indications based on a measurement procedure performed in industrial conditions.
\end{abstract}

Keywords: rolling bearings; frictional moment; industrial measurement; quality control

\section{The frictional moment as an important parameter in the evaluation of rolling bearings}

Despite the fact that losses related to friction in rolling bearings are incomparably lower than in slide bearings, they have a large impact on the efficiency of machines and mechanical devices. Friction losses in rolling bearings are caused, inter alia, by deformations at the 
contact between the rolling element and raceway, internal friction of the lubricant, slips and micro-slips, cage friction, as well as friction on seals [1,2].

The frictional moment is defined as resistance of the bearing when trying to rotate one ring in relation to the other, and it depends to a greater or lesser extent on the following factors:

- type, variant and dimensions of the bearing,

- load values and its direction,

- rotational speed,

- type and properties of the lubricant and the method of lubrication.

It is possible to theoretically estimate the frictional moment, which is the sum of two sections [3]:

$$
M=M_{0}+M_{1}
$$

- $M_{0}$ - section of the equation independent of the load, Nmm:

$$
\begin{array}{lll}
M_{0}=f_{0} \cdot 10^{-7} \cdot(v \cdot n)^{2 / 3} \cdot d_{m}^{3} & \text { for } & v \cdot n \geq 2000 \\
M_{0}=f_{0} \cdot 10^{-7} \cdot 160 \cdot d_{m}^{3} & \text { for } & v \cdot n<2000
\end{array}
$$

where: $f_{0}$ - coefficient depending on the type of bearing and lubrication conditions, selected on the basis of tables; $v$ - oil kinematic viscosity, $\mathrm{mm}^{2} / \mathrm{s}^{-1} ; n$ - rotational speed, $\min ^{-1} ; d_{m}$ bearing pitch diameter in $\mathrm{mm}$.

- $M_{1}$ - section of the equation dependent on the bearing load, Nmm:

$$
M_{1}=f_{1} \cdot P \cdot d_{m}
$$

where: $\mathrm{P}$ - equivalent load, $\mathrm{N} ; f_{1}$ - factor depending on the type and size of the bearing and the permissible static load coefficient. 
Research on the frictional moment is especially important for nodes where power losses are of high importance. Similar works are undertaken by many research centres, as well as by leading bearing manufacturers. They focus on isolating factors causing an increase in frictional resistance in bearings and striving to reduce influence of those factors. All these efforts create the need to build devices that allow to precisely measure the tested bearings friction torque and its subtle changes depending on the fluctuation of factors influencing its growth [4,5]. Rolling bearings manufacturers are at the forefront of the run, as the pressure of competition forces them to strive to minimize the frictional moment in the bearings they produce. This has a positive impact on the reduction of energy demand necessary to drive bearing supported components in various types of machines, devices and vehicles [6,7]. It is often necessary to use bearings with low or controlled moment of friction in devices manufactured at small scale. In such cases, engaging enormous research resources to work on reducing the frictional moment is unjustified and too costly. It is then more reasonable to select an appropriate bearing designed from existing designs, based on the measurements of the frictional torque performed on an accurate and reliable measurement rig [8,9]. The ability to precisely measure the frictional moment values occurring in rolling bearings, as well as the knowledge of the dependence of their values on the conditions in which the bearings operate, including factors such as rotational speed and load, allow the machine/device designers to select the optimal bearing for a specific structural node, and allow bearings manufacturers to assess their quality and to take the right paths for improving their designs [10].

In the available sources, one can find both descriptions of test rigs measuring the frictional moment of bearings intended for research purposes, as well as commercial offers of companies producing professional measuring equipment $[11,12,13,14,15,16,17,18,19]$. Industrial measuring devices at the disposal of companies producing rolling bearings are, however, an uncommon object of scientific research.

The test rigs used to measure the frictional moment, depending on the purpose of the objects tested, are suitable for tests with axial or transverse loads applied. Due to technical difficulties related to the construction of a devices used for torque measurement with simultaneous application of both axial or transverse loads, devices able to perform such tests are rare. All devices used to measure the frictional moment in rolling bearings have components necessary to perform the testing procedures on the given test rig. These include the following components: test head, drive module, load module, control system, measurement data acquisition and processing system, as well as the body of the test rig and its accessories. 
The test head must ensure repeatable testing conditions for the tested bearing. This is a precondition to ensure reliable comparison of results. The most dangerous for the node with the tested bearing is the introduction of interactions that go beyond the measurable load values in the directions controlled by the system supervising the testing process, especially the forces that may act in such a way that the bearing rings overlap each other. Solutions introduced by the testing equipment manufacturers are aimed at obtaining the best possible coaxiality and/or perpendicularity of the mated subassemblies, and where possible, introduce a margin for connection flexibility to prevent excessive stiffness of the system. The key issue of the test head assembly design is measuring method of the frictional moment value generated by the tested bearing. Especially that the measurement must be taken at different loads. The assembly transmitting the torque value to the measuring system must do so lossless or at least with a controlled loss included in the result obtained.

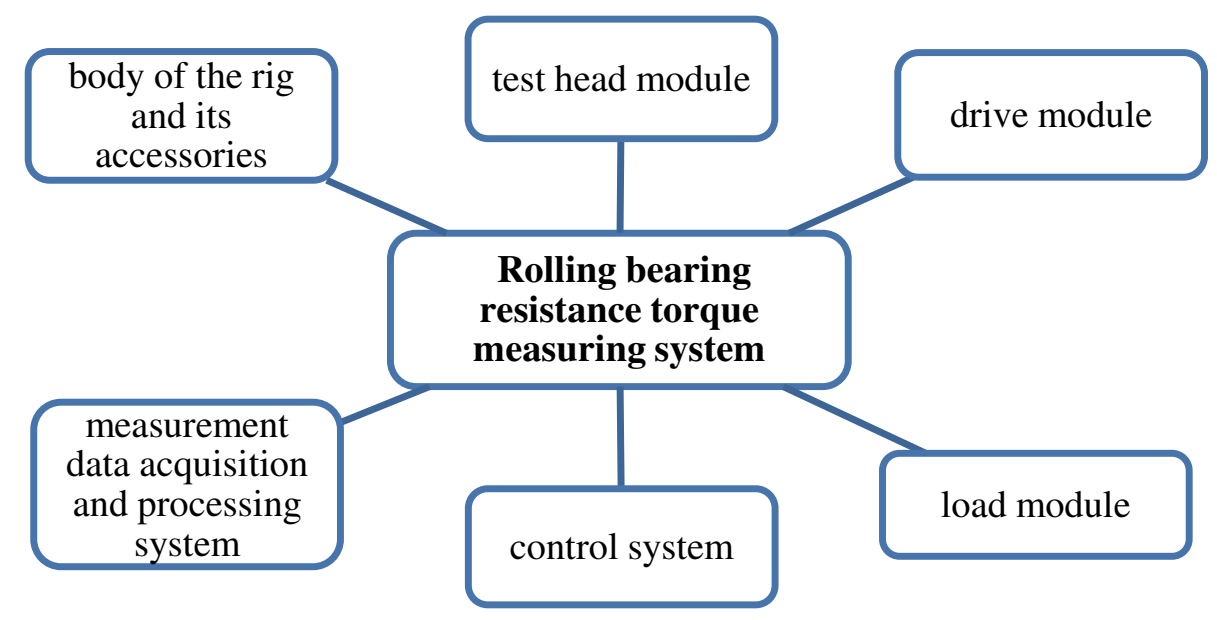

\section{Fig.1. Design features of the measuring system used to test the frictional moment of rolling bearings.}

The spindle drive of the torque gauge should accurately reproduce the rotations set by the control system and keep them stable during the measurement. Manufacturers of torque measuring devices typically use one of two spindle and test head power transmission systems. Some designs have the motor in line with the spindle, while other designs transmit the drive through a belt transmission. Each of the designs has its advantages and disadvantages. The advantage of placing the motor in line with the spindle is the possibility to read the rotation of the tested bearing directly. Especially if a servo drive is used as the drive unit. The introduction of a belt transmission, especially in applications requiring low revolutions and 
intended for measuring torques of high values, allows to obtain the required torque at lower engine power and significantly reduces the impact of its natural vibrations on the spindle and, consequently, on the test head. The selection of the motor depends on the implemented spindle speed control system.

The test load of the bearing during the test are generated, depending on its size, by gravity, a pneumatic system or a hydraulic system. The design of the loading mechanism is to ensure that the axial (or radial) force at the value set by the test process control system is transferred to the tested bearing. Various designs of the loading systems are used, and their selection depends mainly on the value of applied force. When high value axial loads are required by the test procedure, the force is generally transmitted to the tested bearing via the spindle. When transverse loads are applied, the load is transferred to the bearing through its housing associated with the outer ring. Gravity systems can be used for a limited range of loads. Advantage of the systems based on gravity is the simple structure and high repeatability of the set parameters implementation. The disadvantage, however, is the problematic changing of load value and limited range of application. Systems based on pneumatic actuators are much more convenient to control, but require more complex equipment and appropriate infrastructure. Less frequently used hydraulic systems require a power station and are selected when high test loads are required.

The control and monitoring module is installed to ensure safe operation of the device and to supervise the course of all processes carried out by the testing device. As far as the testing process carried out on the designed test rig is concerned, it is particularly important to maintain and record the parameters determining the conditions in which the measurements are taken. These include the rotational speed of the bearing and the magnitude of the applied load. The control system responsible for implementation of the testing process must effectively cooperate with the software and the drivers software by sending the information from monitoring and sensors. It must also properly react to commands resulting from procedures sent for execution. This control system is partially located directly on the test rig (sensors and amplifiers), and partially in the control cabinet equipped with an operation panel, together with the rig power supply equipment.

Test software is to perform two basic functions. The first one is transferring to the control and monitoring system the procedures necessary for the implementation of the test program, its execution and reacting to irregularities by correcting them or stopping the test rig. The second one is collecting information about conducted measurements, their analysis, development, visualization of results and preparing the test reports. 
Like all measuring devices, the torque measuring device should be equipped with a stable body and anti-vibration feet. The body houses accessories such as media conditioning systems, power supply components, control and measurement systems.

\section{Construction of a new device for measuring the frictional moment of bearings}

The device that is the subject of this article, is one of the eight test systems built at Fabryka Łożysk Tocznych - Kraśnik S.A. under the project entitled "Establishment of the Research and Development Centre in FŁT-Kraśnik SA". The new measuring practices that have been implemented allow for a significant improvement in the quality of the manufactured bearings and for the production of non-standard bearings, increasing the capacity of machines and mechanical devices. The new device allows to control the frictional moment - a parameter that has not been tested at Fabryka Łożysk Tocznych - Kraśnik S.A, as it has not been among the acceptance criteria for rolling bearings. The new device allows to test the frictional moment of the bearings in any configuration of axial load and rotational speed, thus meeting the requirements imposed by the factory's customers. The device can also test the dependence of the mounting height of cone bearings as a function of load, which is an innovative approach for this type of industrial devices. The design work performed allowed for the selection of 5 original design solutions. These solutions apply to both the entire test rig and its individual universal mechanisms, which can be used in other devices of a similar structure. The innovation of the presented test rig is a unique design (unusual in devices of this type), which allows for:

- execution of cone bearing tests (similar devices are mainly used for ball bearings),

- increasing the number and range of test parameters,

- obtaining higher measurement accuracy.

It should also be mentioned that works on the bearing frictional moment is important in terms of environmental protection, as striving to minimize frictional resistance increases the overall efficiency of the devices, thus reducing $\mathrm{CO} 2$ emissions to the atmosphere.

The new device for measuring the frictional moments of cone bearings is based on several plates, mounted on four columns. Some of these plates are fixed in place with clamping blocks, while others move on linear bearings. A pneumatic actuator located on a fixed top plate drives the module that houses a spindle and a drive. This movement enables coupling and decoupling the drive with the test rig accessories. Under the movable plate with 
the pneumatic table, there is a force gauge measuring the load applied to the bearing. The central part of this device is a rotary table supported with an air bearing. This solution ensures the rotation of the table top with minimal losses. A measuring table is attached to the table top. The mechanism located next to the pneumatic table contains two opposing force sensors. A clamping bar moves between them, which is rigidly connected to the measuring table. The tested bearing is mounted in the special test fixture intended for a given type of bearing. The inner ring of the bearing is seated in the lower part of the fixture, which is connected to the measuring table, while the outer ring is seated in the upper part of the fixture, which is coupled with the spindle during the test.
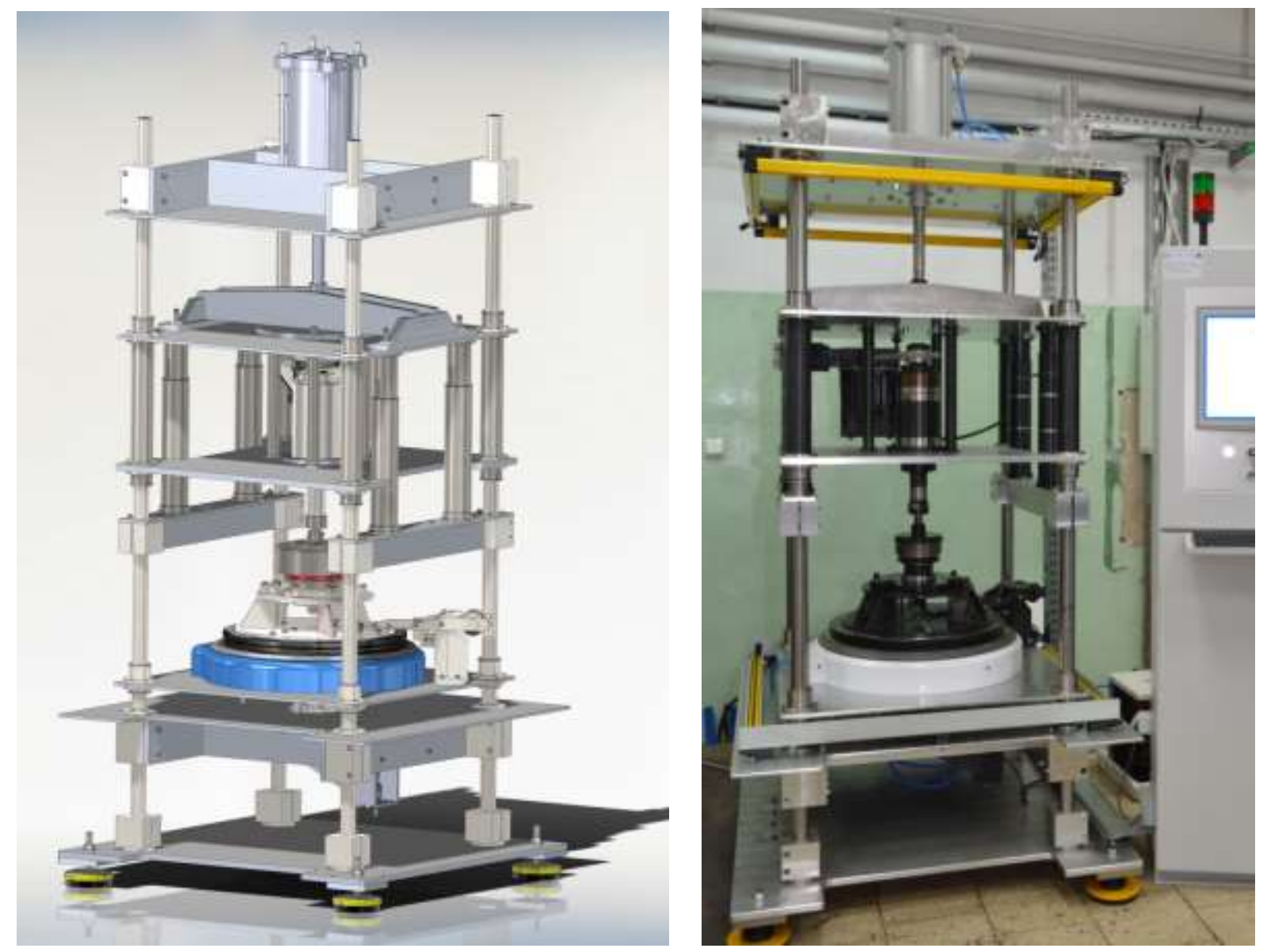

Fig. 2 The new test rig for measuring the frictional moment of rolling bearings a) virtual model, b) prototype implemented at Fabryka Łożysk Tocznych - Kraśnik S.A.

Rotation of the outer ring (driven from the outside) causes the rolling elements to roll on the raceways, and the friction inside the bearing causes the inner ring to rotate freely, trying spin the entire measuring table. The pressure bar presses the sensor with a force proportional to the frictional resistance caused by the bearing operation. Higher resistance of the tested bearing (e.g. poor workmanship or a factory defect) causes the greater force to be indicated by the 
force sensors. The critical level of friction torque generated by a given bearing type is defined by internal company standards or requirements imposed by the customer.

\subsection{Measuring table assembly}

The measuring table assembly is the central part of the device where the actual measurement of the tested object is taken. The plate on which the measuring table assembly is placed is movable and is mounted on the columns by means of linear ball bearings, which enable it to move freely in the vertical direction. This is required to ensure proper functioning of the device, because the pressure the plate generates allows the measurement of the force acting on the tested bearing. The pneumatic table on which the measuring table assembly with the tested bearing and the necessary accessories is mounted is designed not to resist the inner ring of the tested bearing during the test, thus allowing for a lossless measurement of the frictional moment generated by the bearing loaded with high axial force, which is forced to rotate at the required rotational speed by means of the outer ring. A frame is mounted on the pneumatic table, allowing for the alignment and levelling of the measuring table assembly in relation to the loading-driving system. The lower part of the test fixture, having direct contact with the inner ring of the tested bearing, is connected to the frame by means of a steel pin. The outer ring of the bearing is located in the upper part of the fixture, which is coupled to the drive during the measurement. Thanks to this design, the rotation of the outer ring caused by the resistance created in the bearing causes the spontaneous rotation of the pneumatic table. The table has been adapted to test an extensive range of bearings. The measurement table assembly with the test accessories model is presented in Figure 3.
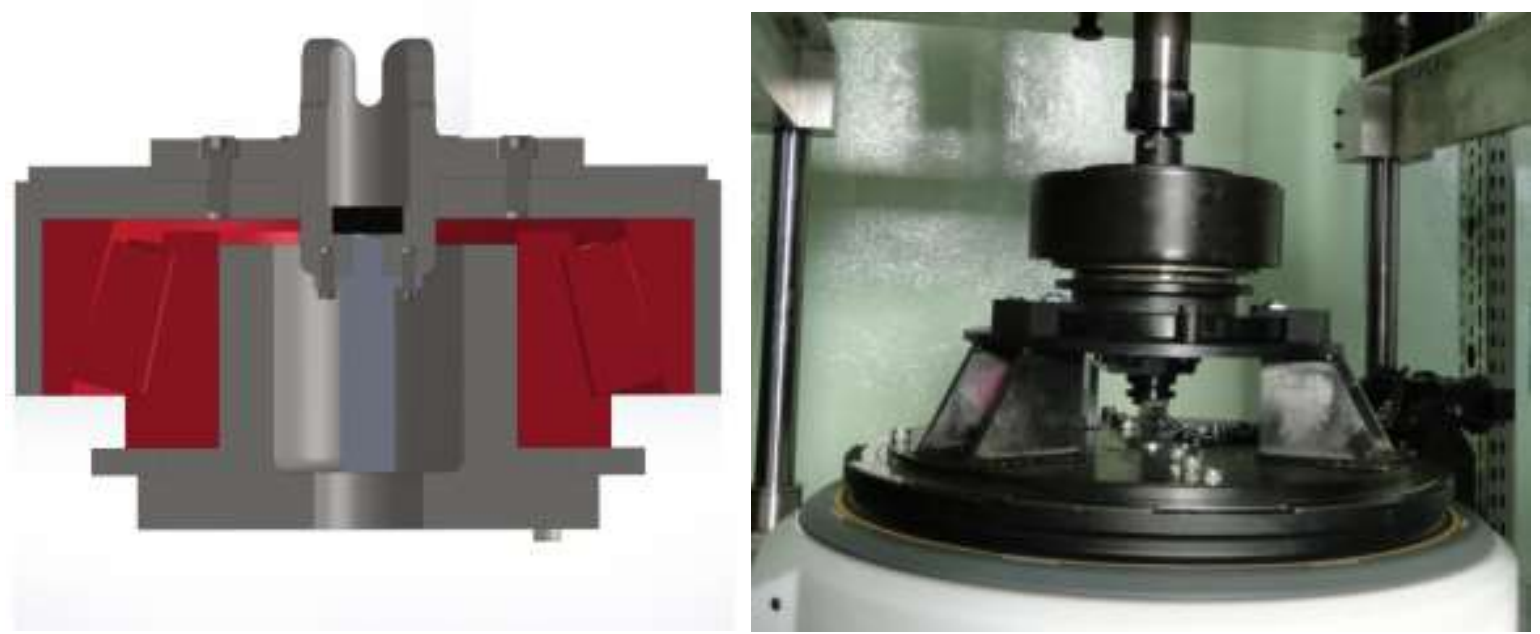

Fig. 3. a) cross-section of the measuring accessories assembly, b) measuring table assembly. 
In addition to the measuring table assembly, a frictional moment measurement subassembly is installed on the same plate, allowing to perform the most important task for his device. This subassembly is shown in Figure 4. The frictional moment is measured by means of two force gauges installed in opposite direction, which enables the measurements to be taken in both directions of rotation of the tested bearing. The pressure is transferred through the pressure bar attached to the base of the measuring table. It exerts pressure on one of the force gauges (depending on the rotation direction of the bearing) with a force proportional to the resistance of the tested bearing. The value of this force, multiplied by the arm length, which is the distance from the force gauge contact point with the measuring bar to the pneumatic table axis of rotation is the value that determines the frictional moment of the tested bearing. The design of the subassembly protects the force gauges against overload, which could damage them if the tested object reaches a frictional moment greater than the maximum assumed (e.g. as a result of bearing seizure). The protection is provided by a system of tilting arms on which force gauges and adjustable fenders are installed, limiting the possible movement of the pressure bar. The maximum pressure, and thus the load on the force gauges, controls the position of the overload protection spring.
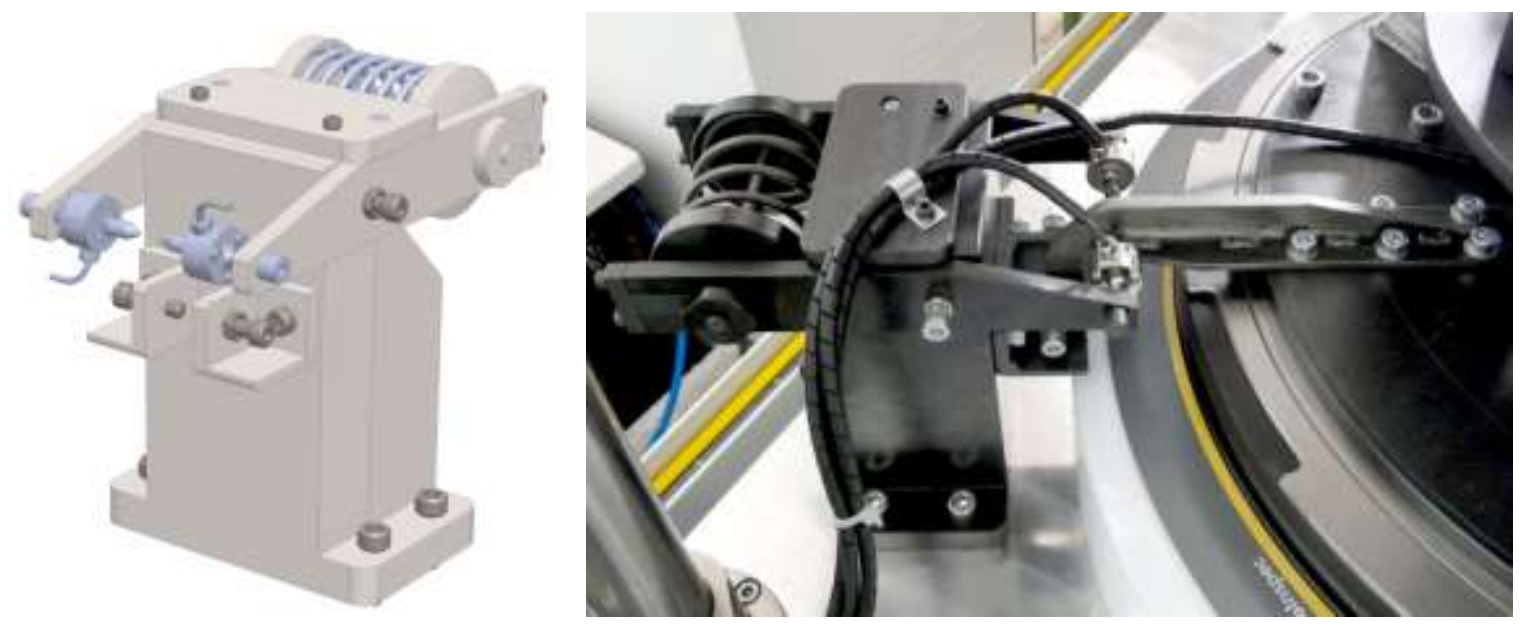

Fig. 4. a) model of the torque measuring unit, $b$ ) measurement of the frictional moment

An additional function of the device is the ability to measure the change in the width of the cone bearing caused by the applied load (displacement between the bearing rings in the axial direction). The displacement sensor positioning subassembly installed in the test zone allows to monitor changes in the height of the bearing as a function of the axial load during the test. The subassembly is fixed to the frame plate so as to be stationary in relation to its axis. Its cylindrical part is filled in the alignment hole and forms the basis for attaching the test accessories to the bearing. The subassembly is shown in Figure 5. The design of the 
subassembly is based on an eddy-current sensor and allows measurements to be made with an accuracy of $1 \mu \mathrm{m}$. The worm gear that drives the sensor support screw is responsible for the precise positioning of the sensor. A sensor is mounted in the head of the load-bearing screw. The axial plays in the worm wheel and plays in the screw thread are removed by springs. By one full turn of the worm wheel, the sensor moves approximately $0.2 \mathrm{~mm}$ vertically. This ratio allows for precise zero adjustment of the sensor position in relation to the bearing outer ring before starting the test. The assembly is rigidly fixed to the bottom of the test accessories and detects displacement of the shaft connected with the top of the test accessories. The measuring shaft, the displacement of which is formally measured, is shown in the crosssection in Figure $3 \mathrm{a}$.
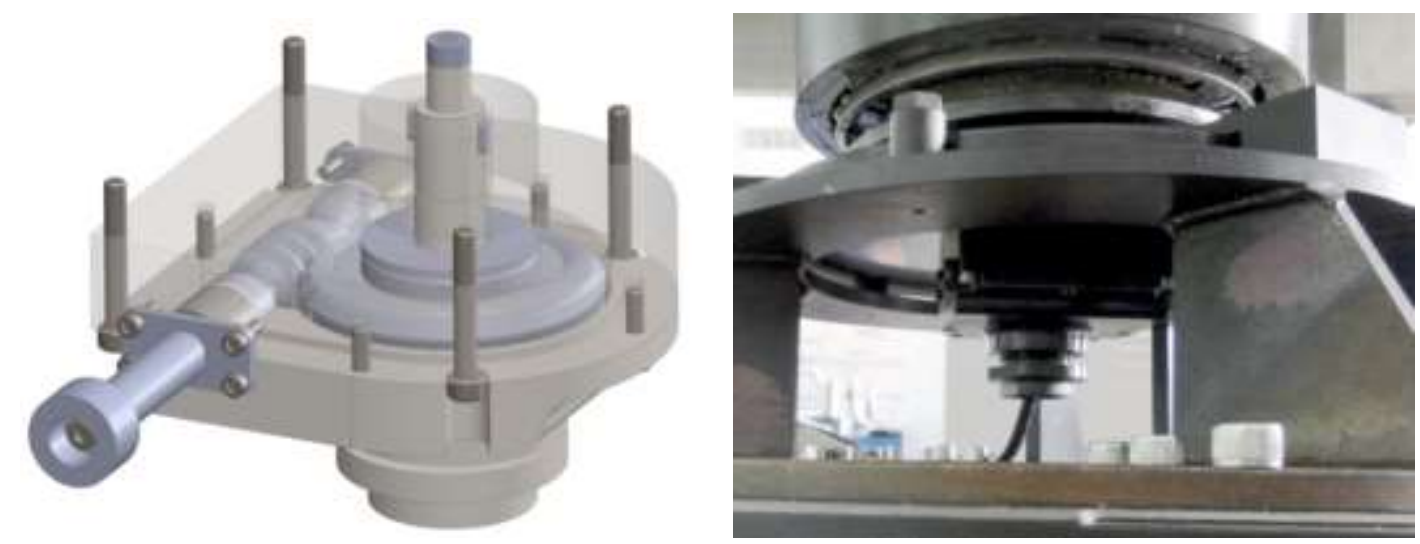

Fig. 5 a) Model of the assembly height measuring unit b) Location of the assembly height measuring unit.

\subsection{Force gauge relieving lever assembly}

The plate under the measuring system plate is permanently attached to the torque measuring unit columns by means of clamping blocks, to which it is fixed by means of a sleeve with a flange. The sleeves must ensure the hole and the outer diameter are in line so as not to introduce errors in the spacing of the holes of all plates that constitute the structure of the device. A precise force gauge is installed on this plate to measure the test load during the test. A ball encapsulated in a sleeve having a conical bore presses the dynamometer. This sleeve is screwed to the underside of the movable plate with the entire measuring system.

Under the plate, there is a lever mechanism to relieve the force gauge during breaks between tests and when the device is not powered. This subassembly is constructed in such a way as to enable lifting of the table above the pressure gauge by means of a set of springs, which exert pressure on it with appropriate force by means of a circular cam and two pins. When the device is being operated, the pneumatic actuator counteracts the pressure of the 
springs and lowers the spindles, freeing the measuring table and allowing measurement of the pressure. Due to the large gear ratio, the spring package and the actuator operate in the range of forces ten times smaller than the mass of the table with the test accesories. The use of such a mechanism increases the durability and technical efficiency of the force gauge.
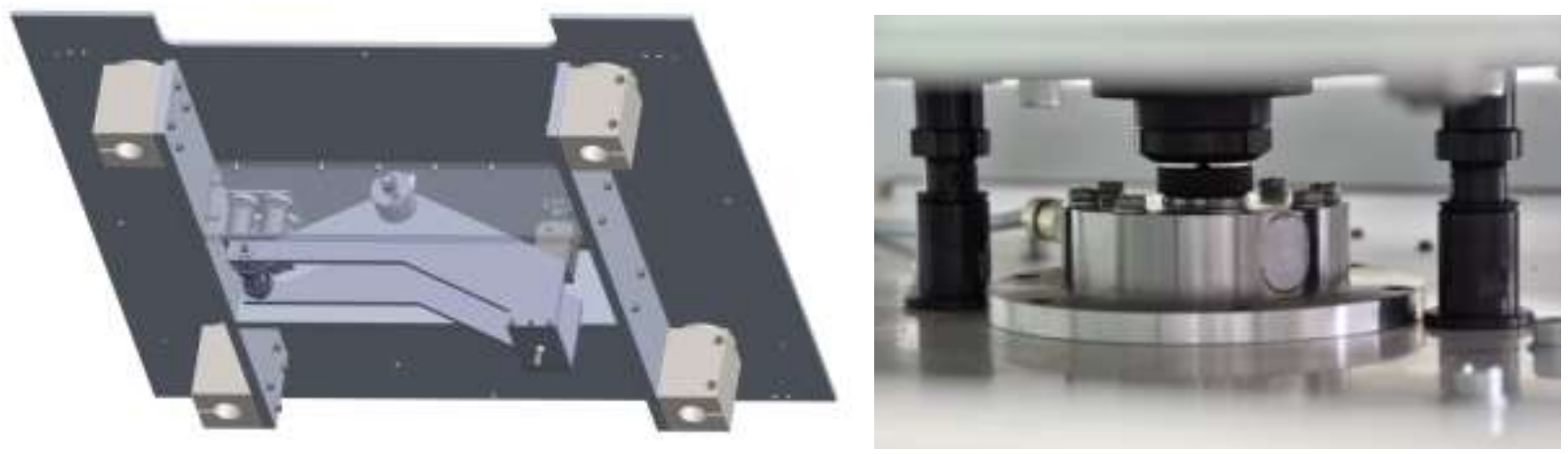

Fig. 6 a) Model of the lever relieving the force gauge. B) Measurement of the axial force

\subsection{The power and load transmission unit}

The power and load transmission unit plays a role of a complete power unit and an indirect load transmission unit from the pneumatic actuator. This unit has a form of a cage and includes a drive consisting of a spindle equipped with a motor and a belt transmission, being at the same time an intermediate element transmitting the load exerted by the pneumatic actuator to the tested bearing. Four tubes guide the assembly along the columns. They link three load bearing posts with load-bearing plates, forming a compact integrated unit. The tube guides are supported by four pairs of linear ball bearings. Very important parameters determining the correct functioning of this unit are the equal length of the posts and the separation provided by the bearing tubes and, as in the case of all six supporting plates, the appropriate spacing of the holes leading to the columns.
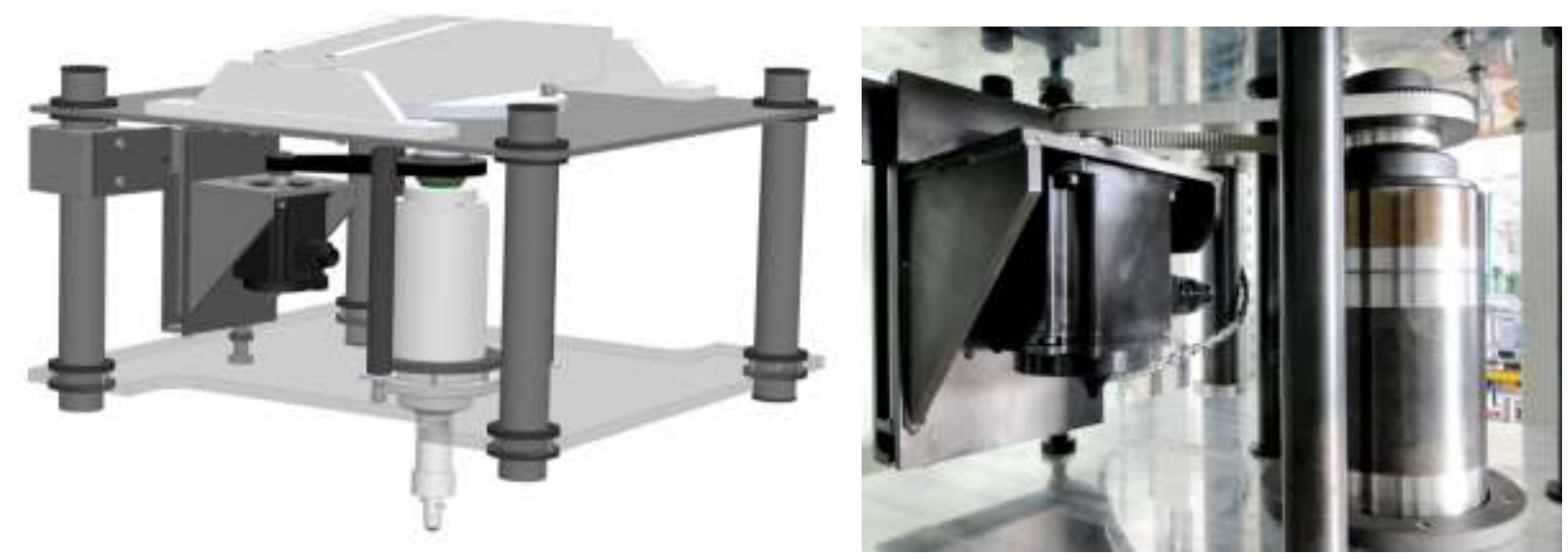

Fig. 7 a) Model of the power and load transmission unit b) Drive unit with the spindle 
The power unit is fully assembled into the power and load transmission unit. The spindle, mounted in the centre of the bottom plate of the assembly, is inserted from the bottom and screwed with a ring attached from above. The servomotor is suspended on a rotatable mounted support, which has a wide range of adjustment its position in relation to the spindle. The tensioner is mounted on a bearing tube with a block clamp. Figure 7 shows the cage model and the spindle with the drive.
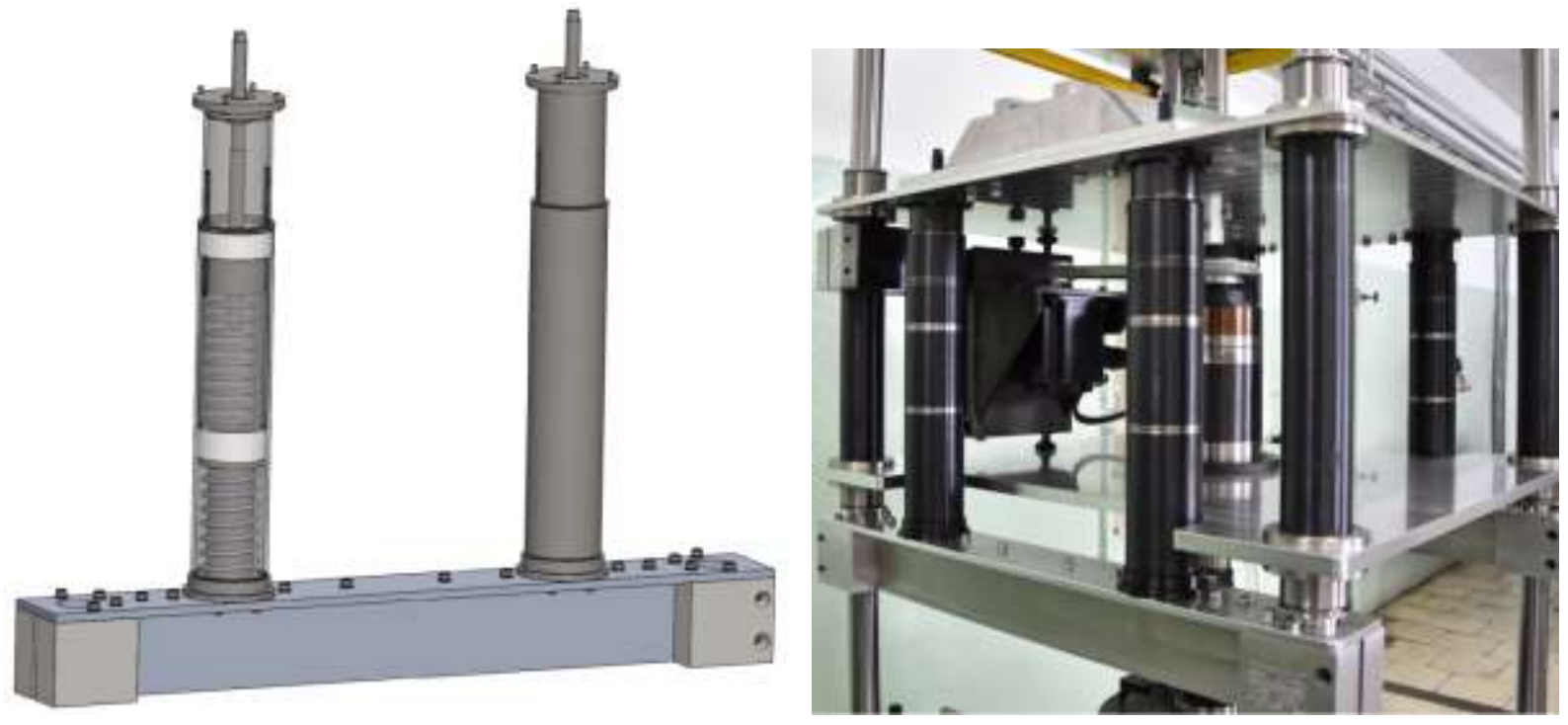

Fig. 8 Shock absorber model. Shock-absorbing suspension of the power and load transmission unit.

To ensure safety, the cage forming the power and load transmission unit is suspended on the relief assembly, which lifts it up and keeps it in a safe position in any emergency (power outage, compressed air outage, overload of the measuring system or emergency shutdown by the personnel). The general view of the assembly is shown in Figure 8 . The relief assembly consists of a set of four special spring shock absorbers. The assembly is also suspended to a set of loads that is designed to apply the loads predetermined by the program to the tested bearing In addition to ensuring work safety, the relief assembly is designed to keep the spindle at a level that allows for the assembly and disassembly of bearing samples with the test accessories and to disengage the package of accessories with the sample when the test is finished or in emergency cases.

\subsection{Load assembly}

The last, upper support plate is permanently connected to the columns by means of clamping blocks, similarly to the two lower support plates, The plate encapsulates the entire 
structure of the device from above, and at the same time, serves as a platform for mounting the pneumatic actuator and creates a set of axial loads with the cylinder. This unit is coupled with the structure of the power transmission system, so as to ensure the pressure exactly along the axis of the unit. Figure 9 shows design of the assembly. In order to couple the spindle with the measuring system and set the required force, the actuator on the top plate must first overcome the force exerted by the shock absorber springs.

Additionally, In Figure 9b, one can see a chain of light curtain panels. Appropriate pairs of the panels are attached to the main plate of the force gauge relieving lever assembly. Interruption of the invisible light beam flowing between the pairs of the curtain panels results in the automatic stopping of the upper actuator and lifting the power and load transmission unit mechanically.
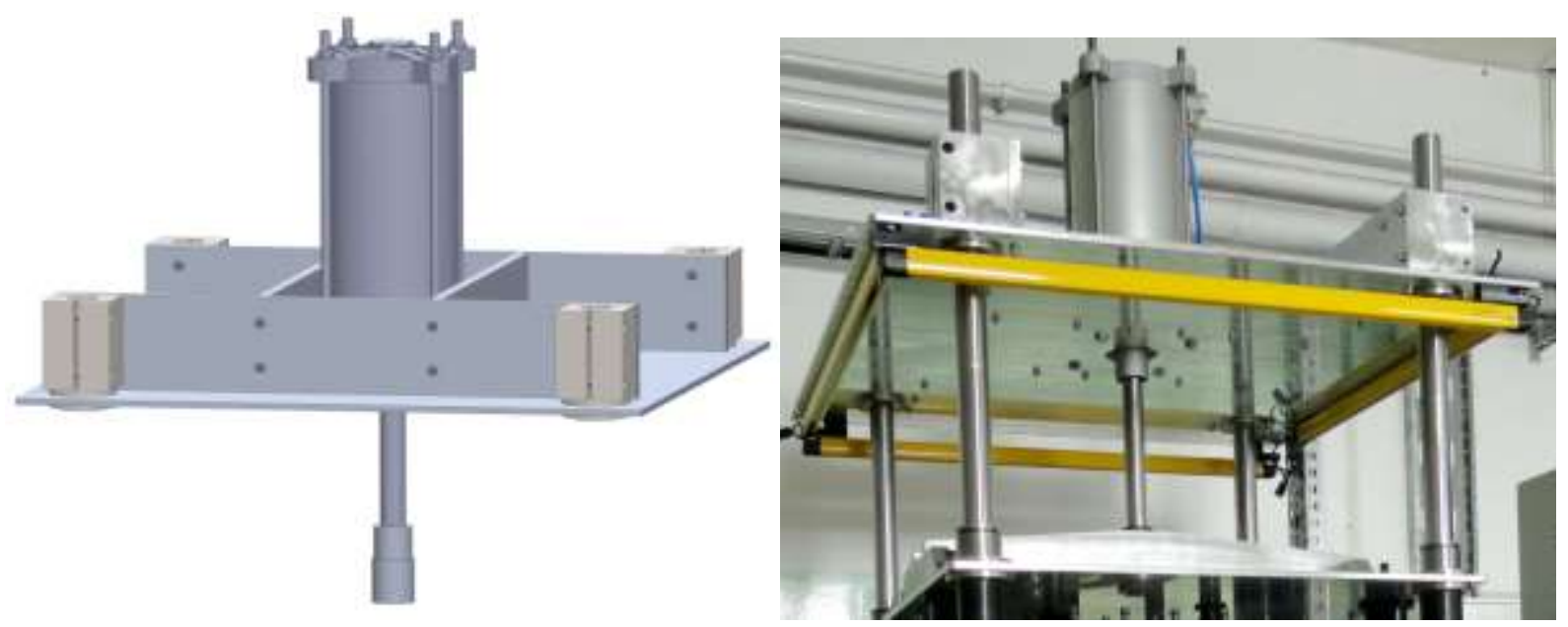

Fig. 9 Load assembly model. Location of the top plate with light curtains

\section{Preliminary tests and test program preparation}

After the first launch of the test rig, preliminary tests were carried out during which the following activities were performed:

- The mass, force and displacement sensors were calibrated.

- Adjustments were made to the height setting of the clamps blocking the plates in order to provide, as much space as possible, for the replacement of the test accessories while using the greatest possible displacement of the upper actuator.

- The degree of parallelism of the stationary plates and the degree of concentricity of the central holes (in plates, measuring table, spindle shaft, etc.) were checked using the coordinate measuring device (mobile measuring arm). 
- The operation of the mechanical units of the device was checked.

- The reaction of assemblies and executive subassemblies to commands of control systems sent by software and directly from the control panel was tested.

- The reaction of the safety systems to simulated threats was checked.

- The measurement sensors indications to the given loads were checked.

The activities performed above proved that the constructed test rig used for measuring the frictional moment value in rolling bearings meets the initial assumptions and the general requirements for this device class. And most importantly, the new device is able to measure new designs of bearings for which the devices used so far cannot be used. In addition, a series of tests of cone roller bearings were carried out in order to assess the general metrological properties of the constructed rig as well as the repeatability of the obtained results. The method of presenting the results shown in Figures 10 and 11 is suited for their presentation in the test report, but does not contribute much to their analysis in terms of the assessment of repeatability of the results obtained by a specific device. It only shows the behaviour of a specific bearing in response to changes to external parameters. In order to evaluate repeatability of the test procedures, the results were compiled in such a way that the trend in their behaviour was visible as a function of subsequent measurements.

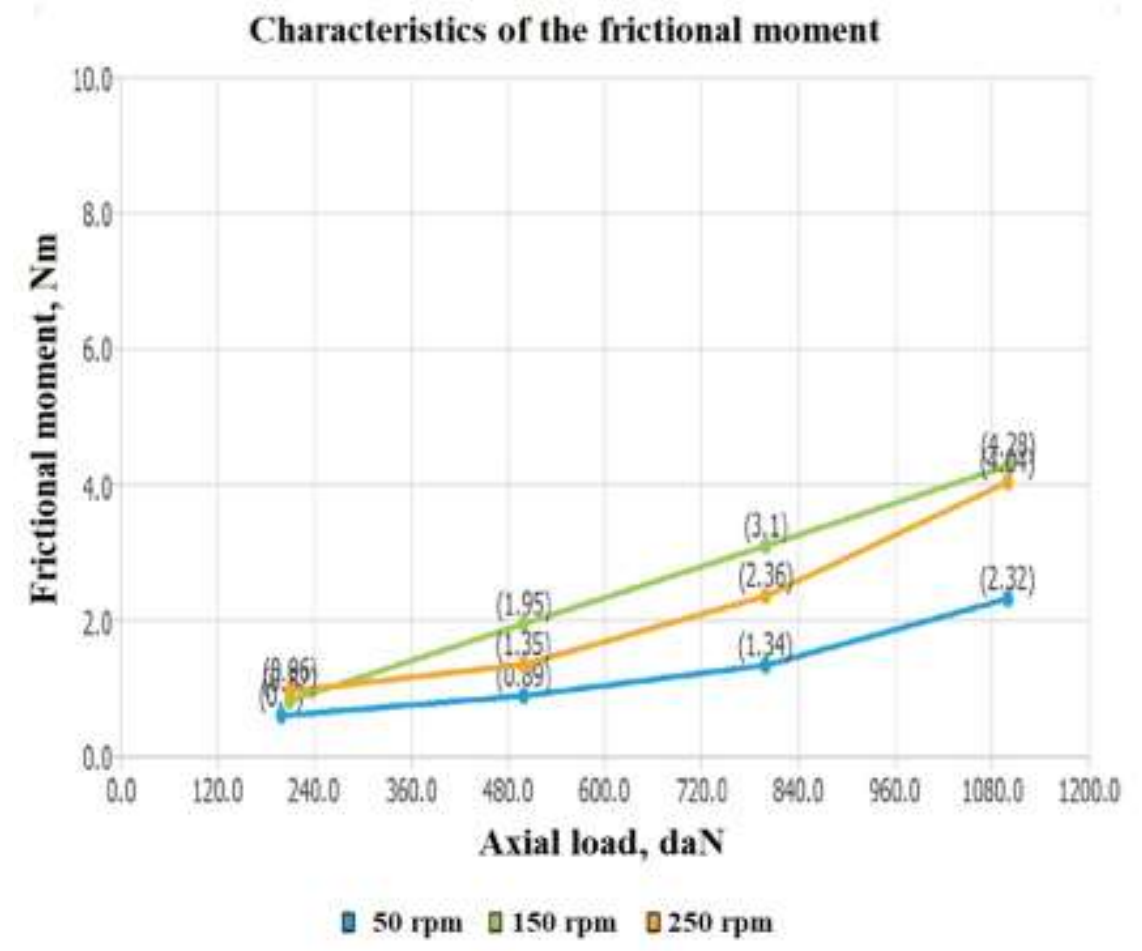

Fig. 10. Chart of the frictional moment value changes as a function of load for various rotational speeds 


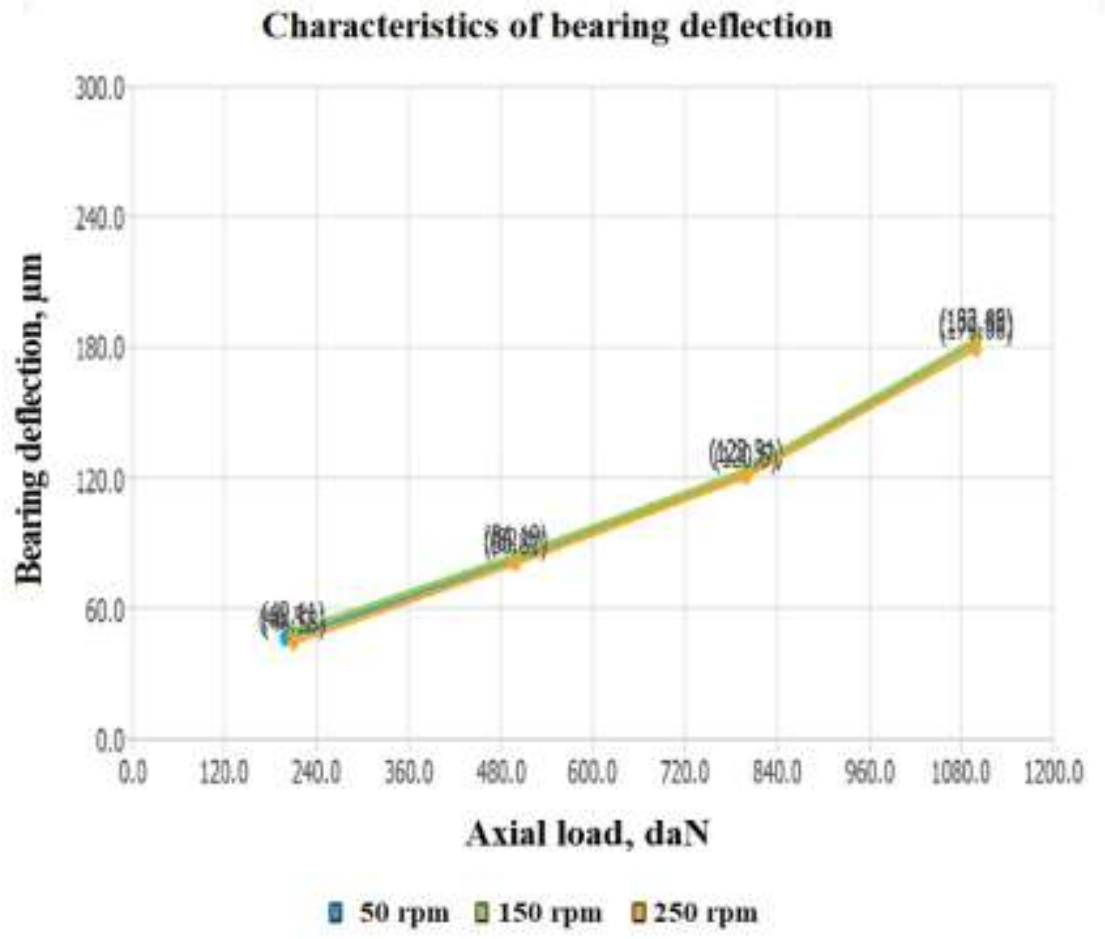

Fig. 11 Chart of changes in bearing height as a function of load for various rotational speeds

Charts showing the successive resistive torque value measurement results obtained for the same parameters are given in Figures 12-14. Charts showing the successive mounting height measurements results obtained for the same parameters can be found in Figures 15-17.

The task of the test program was to establish a forecast of the test results values. Therefore, the test program was prepared for a medium-sized bearing that can be tested ufor the maximum loads achieved on the rig. The obtained results were verified on the basis of a series of frictional moment measurement analysis for a cone roller bearings type 33213. The test program is presented below:

- Five bearings marked as: 1O, 2O, 3A, 4A, 5AT. The numbers 1, 2, 3, 4 and 5 indicate the consecutive bearing number, while the letters indicate the type of lubricant used: $\mathrm{O}-$ Optigear, A - Anticorit, AT - Anticorit. The AT bearing was dismantled before the test.

- The tests lasted one week, and during one day two measurements of one bearing were taken, several hours apart. Thanks to this, the tested bearing had a chance to return to the previous condition before the next test, which should help ensure the highest possible repeatability of the measurement conditions. 
- Each measurement consisted of three stages. Each of them had a different rotational speed, which was respectively 50,150 and $250 \mathrm{rpm}$. For each of these speeds, the axial force that loaded the bearing was changed 4 times: $200 \mathrm{daN}, 500 \mathrm{daN}, 800 \mathrm{daN}, 1100 \mathrm{daN}$.

- Each measurement program was therefore executed as follows: after mounting the bearing in the housing and placing it on the device, the bearing was loaded with an initial force of $50 \mathrm{daN}$. The spindle then accelerated the bearing outer ring housing to $50 \mathrm{rpm}$. After reaching the set rotations, the bearing was loaded with a force of $200 \mathrm{daN}$. Once the torque value was stabilised, the measurement was taken. In the next step the load was increased to $500 \mathrm{daN}$ and the measurement was taken again. The same steps were repeated for the load values of $800 \mathrm{daN}$ and $1100 \mathrm{daN}$. An analogous sequence of measurements with different axial forces was executed after increasing the speed to $150 \mathrm{rpm}$, and then to $250 \mathrm{rpm}$. Once the test was completed, the bearing was removed from the housing and replaced with the next one.

- By using this methodology, a series of 10 frictional moment measurement results were obtained for each bearing at 12 different combinations of rotational speed and load. The examples of obtained results presented in Figures 10 and 11 refer to the measurements of the $3 \mathrm{~A}$ bearing.

- When analysing further graphs, it can be seen that in several cases (two cases for the 3A bearing and one for the $4 \mathrm{~A}$ bearing), negative results were obtained. It is most likely caused by improperly executed force sensor zeroing procedure (the zeroing could have been performed when the gauge was in contact with the measurement bar connected with the table). The obtained information shows that failure to avoid the contact between the measuring bar and the frictional moment measuring unit during the force sensor zeroing procedure (which must be performed before each measurement) may be a source of significant systematic errors.

- In the case of mounting height measurements, improperly executed zeroing procedure can also affect the result. In charts 15-17 one measurement result is missing. It was not included in the charts because was was considered a significant systematic error, causing one series of measurements to be shifted for all bearings by as much as $35 \mu \mathrm{m}$. The inaccurate zeroing of the sensor is well illustrated by the case of the mounting height sixth measurement of the $4 \mathrm{~A}$ bearing. Then all results are clearly shifted by approx. $18 \mu \mathrm{m}$. The second case described is shown to illustrate the problem. 
When analysing the results, it is worth knowing the hypothetical value of the frictional moment, which is calculated on the basis of formulas (1) - (3). By substituting the data on the 33213 bearing geometry, the viscosity of the lubricants used, the selected coefficients characteristic for the cone roller bearings, as well as the test parameters in the form of rotational speed and axial load, the theoretical values of the frictional moment values presented in Table 1 were obtained. The calculated values are indicative, because the frictional moment is very difficult to determine unambiguously by a theoretical calculation. This is mainly due to the fact that the coefficients $f_{0}$ and if $f_{1}$ are determined empirically and it is not an unambiguous value, but only a certain range of the very general three groups of lubricants. Secondly, the model described by the formulas (1) - (3) is the basic model and one of the few models used for the calculations. Original formulas have been developed by SKF, FAG and Timken, and the resulting predicted theoretical value of the resisting torque may differ significantly between the formulas. This is very well illustrated in [3].

Table 1. Theoretical frictional moment calculated for various 33213 bearing measurement parameters given in $\mathrm{Nm}$.

\begin{tabular}{|c|c|c|c|}
\hline \multirow{2}{*}{$\begin{array}{c}\text { Rotational speed } \\
\text { rpm }\end{array}$} & \multirow{2}{*}{$\begin{array}{c}\text { Axial load } \\
\text { daN }\end{array}$} & \multicolumn{2}{|c|}{ Lubricant type } \\
\cline { 3 - 4 } & 200 & 0.36 & 0.38 \\
\hline 50 & 500 & 0.77 & 0.80 \\
\hline 50 & 800 & 1.19 & 1.22 \\
\hline 50 & 1100 & 1.60 & 1.63 \\
\hline 50 & 200 & 0.44 & 0.50 \\
\hline 150 & 500 & 0.86 & 0.92 \\
\hline 150 & 800 & 1.27 & 1.33 \\
\hline 150 & 1100 & 1.69 & 1.75 \\
\hline 150 & 200 & 0.51 & 0.59 \\
\hline 250 & 500 & 0.92 & 1.01 \\
\hline 250 & 800 & 1.34 & 1.42 \\
\hline 250 & 1100 & 1.76 & 1.84 \\
\hline 250 & & & \\
\hline
\end{tabular}




\section{The results of the frictional moment test}

The chart below show the results of all the frictional moment tests performed, arranged in a way allowing visual assessment, both in terms of changes resulting from differences in the set test parameters, as well as changes in the lubricants. They also make it possible to observe the importance of the process of mounting bearings for testing, as well as the precision of zeroing the measuring sensors before starting the test.

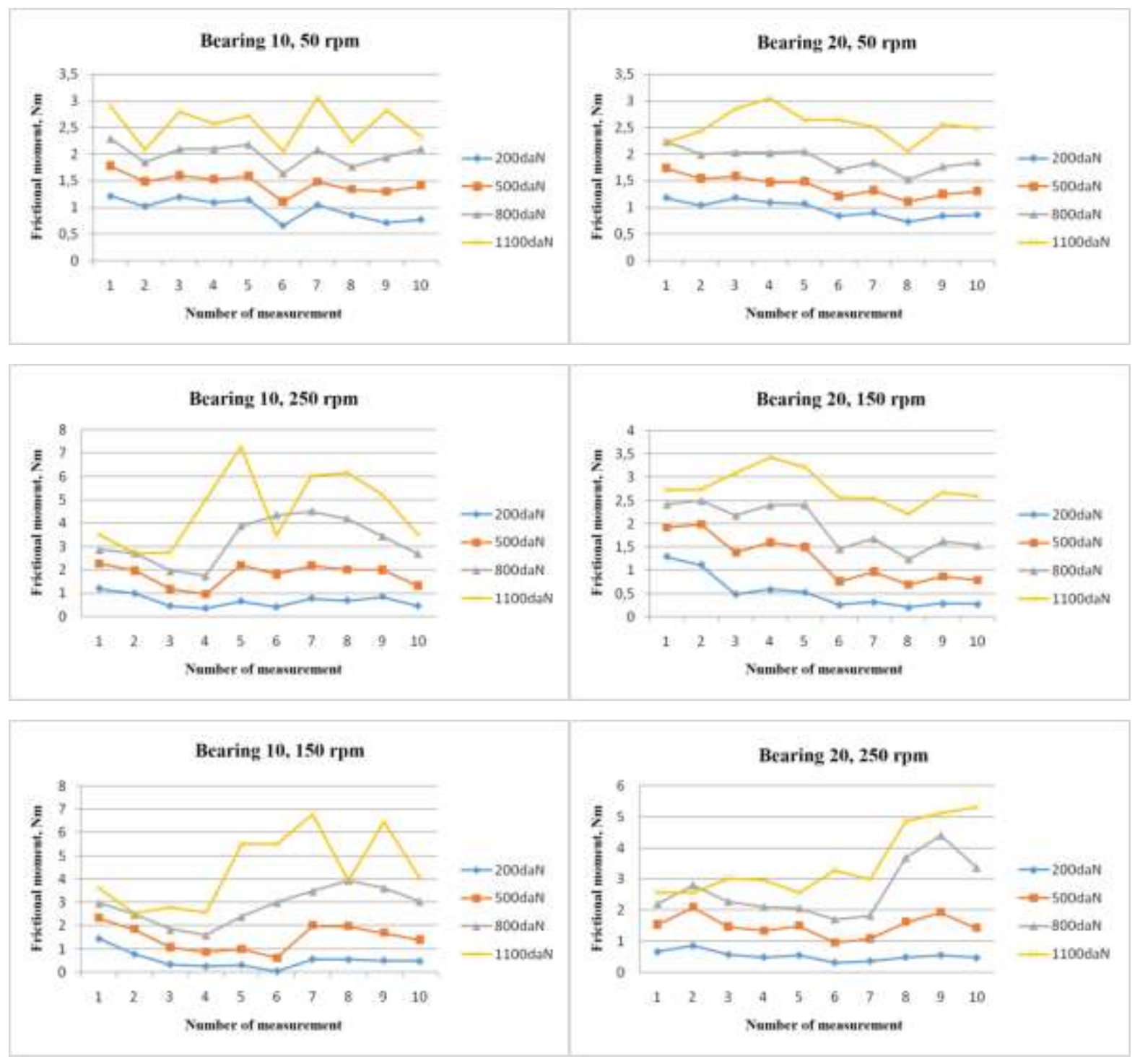

Fig. 12 a) Bearing 10 measurement series, b) Bearing No. 30 measurement series, 


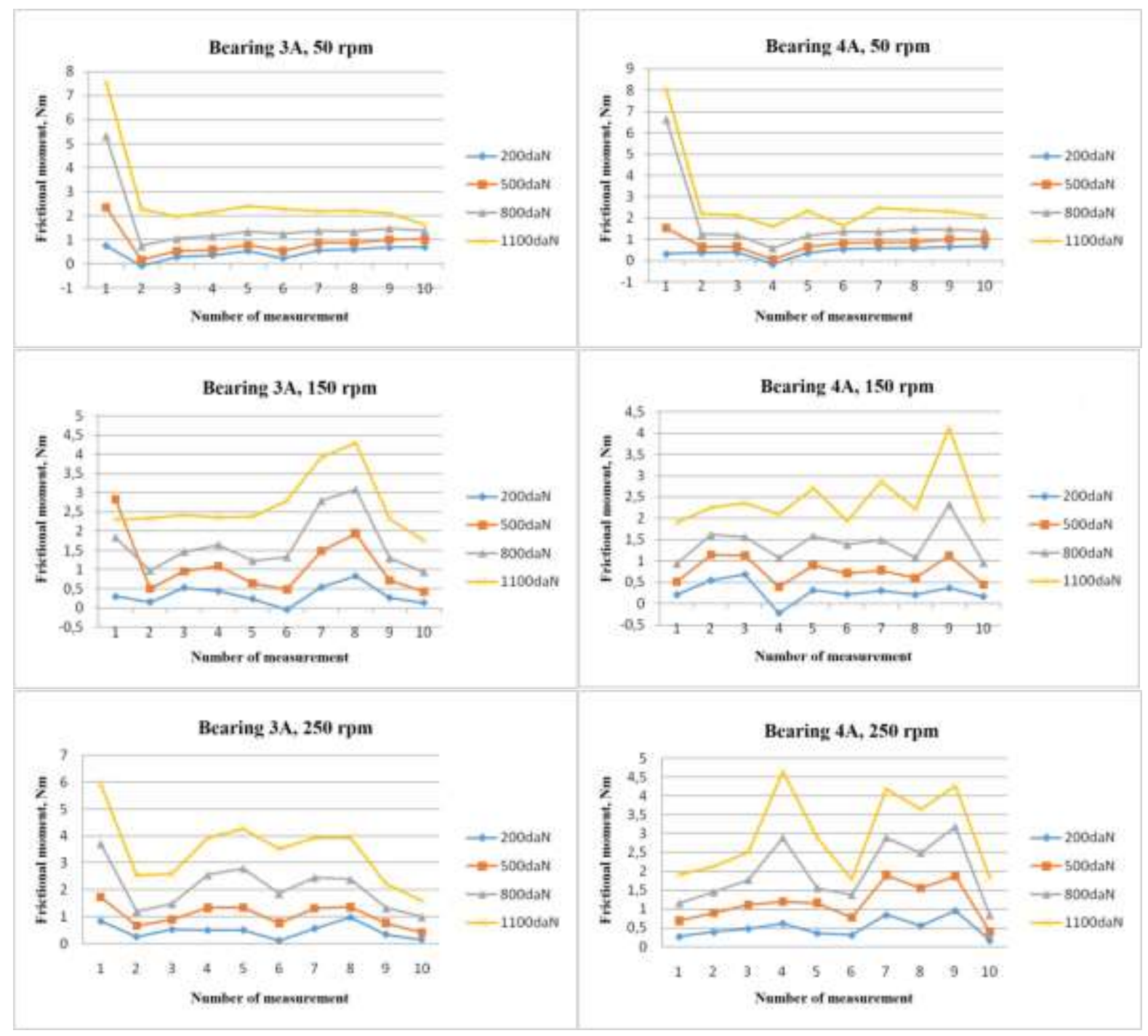

Fig 13. a) Bearing No. 3A measurement series, b) Bearing No. 4A measurement series

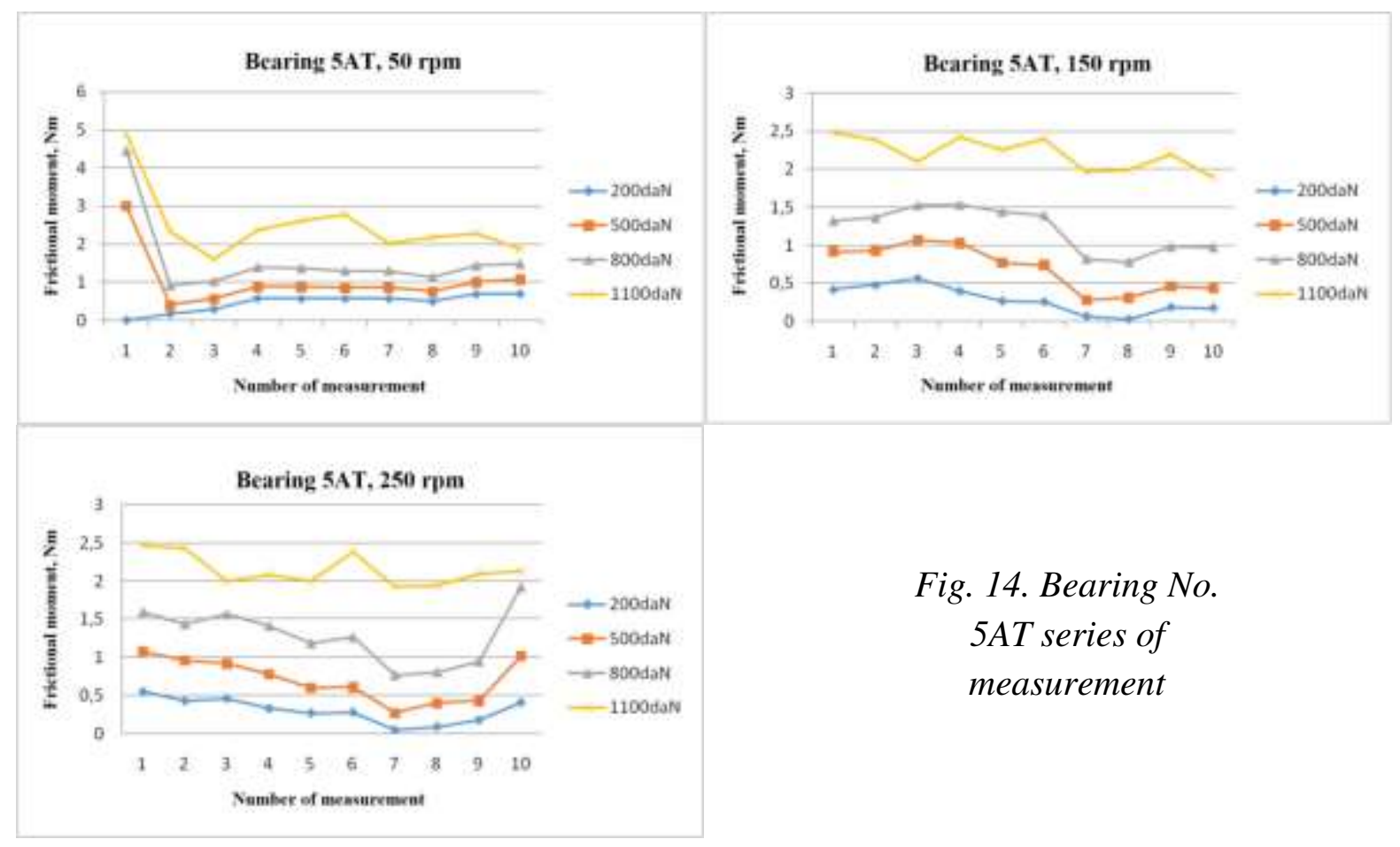


The analysis of the obtained data on the tested torque allows the following conclusions to be drawn:

- The variability of the measurement result of the rolling bearings resistance torque values in a significant part of the obtained data can be considered rational. In some cases, the first measurement is at the same level as the following measurements (e.g. bearings 10 and 2O). This is the case when the bearings are dismantled before the test. When the bearings are still not worn in, the values are too high during the first measurement (bearing 3A, as well as $4 \mathrm{~A}$ and $5 \mathrm{AT}$ for the initial speed of $50 \mathrm{rpm}$ ). The values obtained from subsequent measurements remain at a similar level or gradually decrease (such an effect is obtained with the use of a speed of $50 \mathrm{rpm}$ ). Sometimes an increase in the resistance torque is observed for the last few tests (in most cases at the highest rotational speed, which is $250 \mathrm{rpm}$ ). Functions for a specified rotational speed value are corresponding (correlated). The only difference is the frictional moment value, which always increases consistently when the load is increased. The exception is the function for the force of $1100 \mathrm{daN}$, which sometimes does not follow the trend set by the previous load values. Presumably, the bearing has inadequate operating conditions for such a high load if lubricated with a lubricant of relatively low viscosity. As a result, the frictional moment behaviour is unstable. This is especially true when measuring the 10 bearing.

- The phenomenon of consistent duplication of the function curve when using the same rotational speed may also indicate the impact of the bearing fixture mounting method, incorrect zeroing of sensors or changes on of the bearing mating surface that occurred in previous tests (especially if the lubrication did not effectively fulfil its function).

- The variability of the results is rising together with the rotational speed increase. The lowest variability was noticed for the rotational speed of $50 \mathrm{rpm}$. The measurement uncertainty depends mainly on the stability of the tested bearing, and not on the testing device itself. This is confirmed by the increase in the dispersion of the results along with the growing research parameters, creating more and more difficult conditions for maintaining the elastohydrodynamic film. The curves obtained during the tests show that the most stable operation of the bearing is at $50 \mathrm{rpm}$, so it can be roughly assumed that the dispersion obtained for this speed is the dispersion closest to that dispersion caused by the testing device itself. 


\section{Bearing width changes test results}

The below charts show the results of all the tests of changes in the deflection of the bearings (displacement of one bearing ring relative to the other), arranged in a similar way as in the case of the frictional moment measurements. They show high stability, which allows for a positive assessment of the selected method for the parameter measurement.

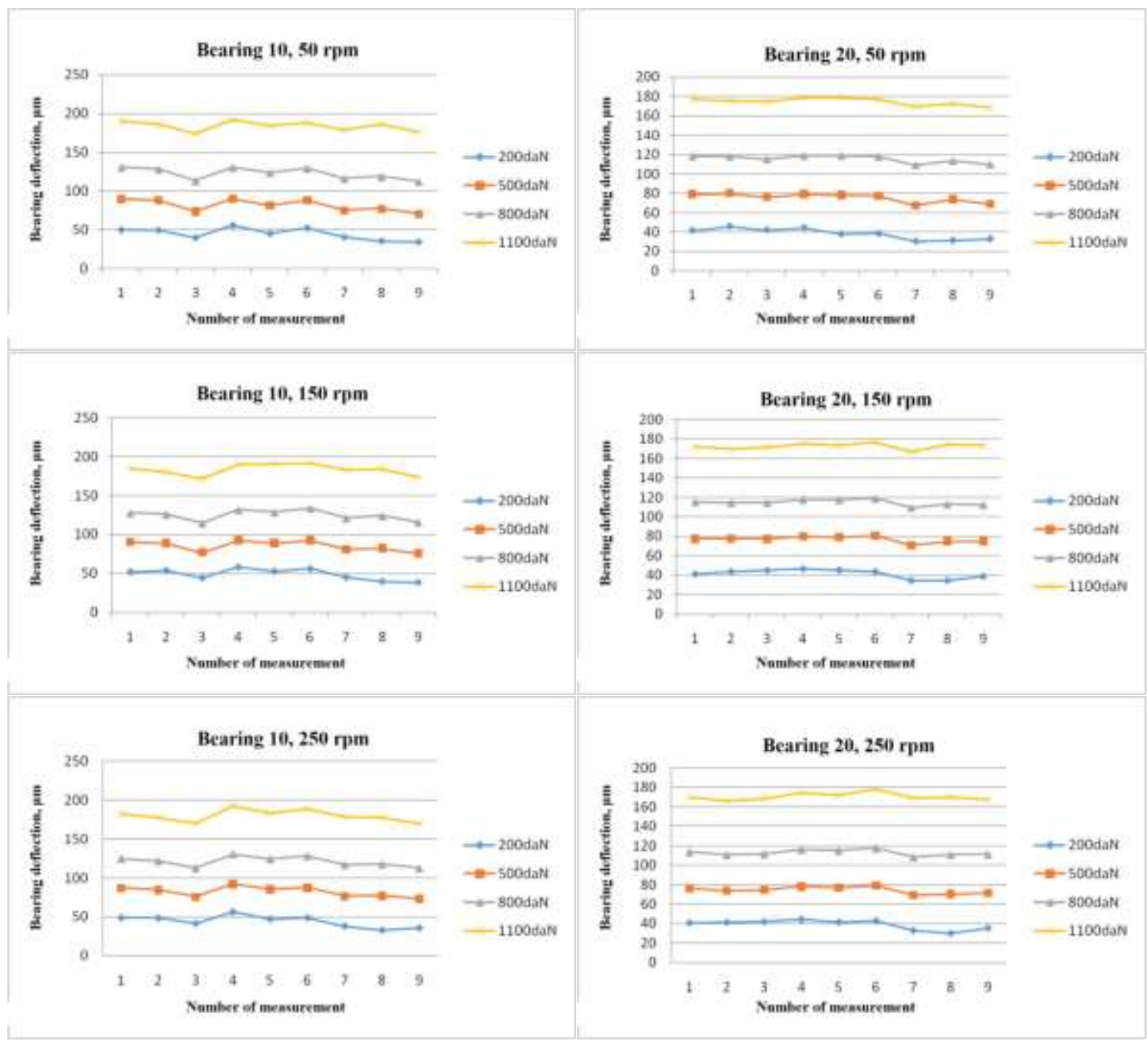

Fig. 15 a) Bearing $1 O$ deflection $b$ ) Bearing $2 O$ deflection 


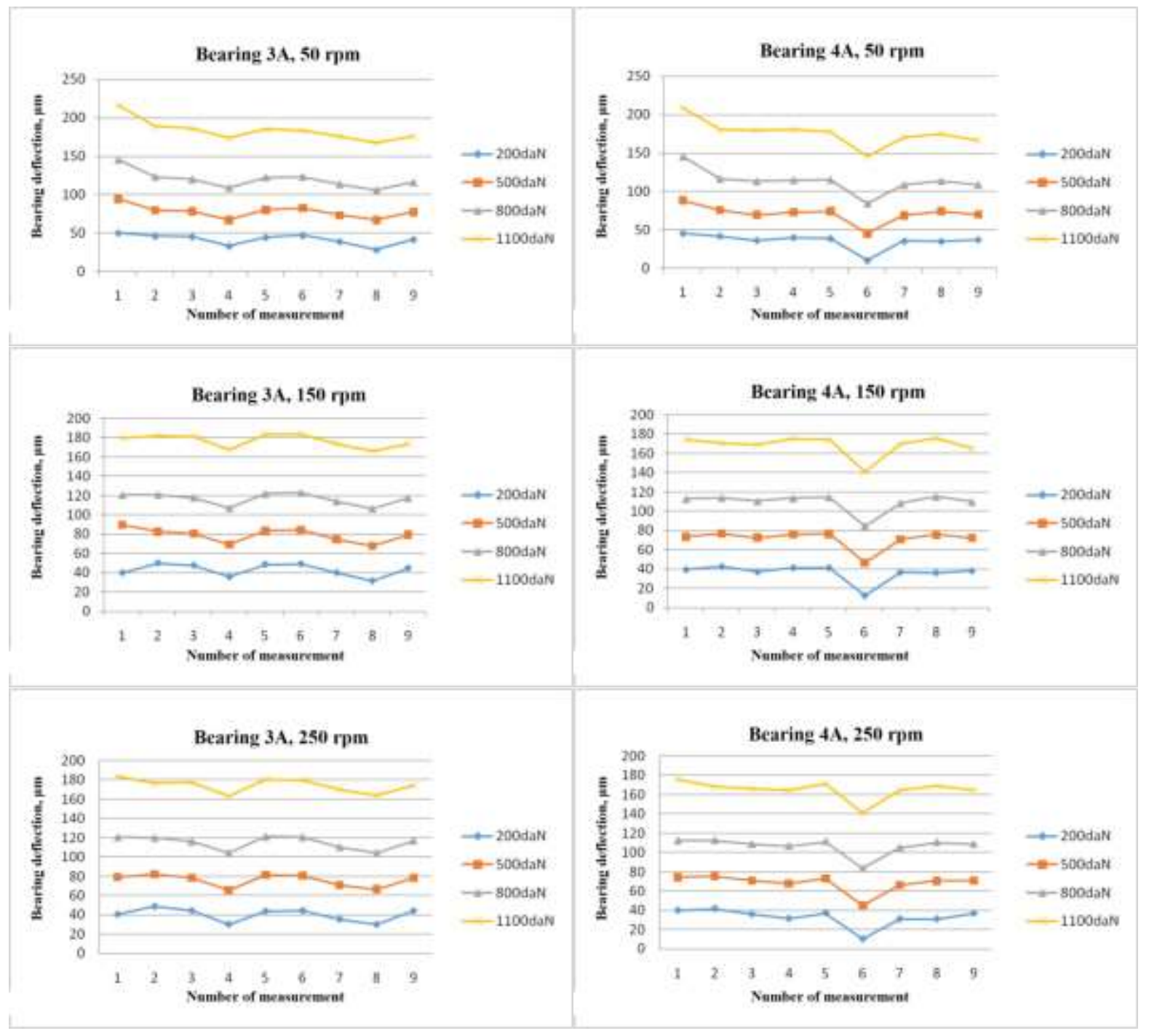

Fig.16 a) Bearing $3 A$ deflection b) Bearing 4A deflection
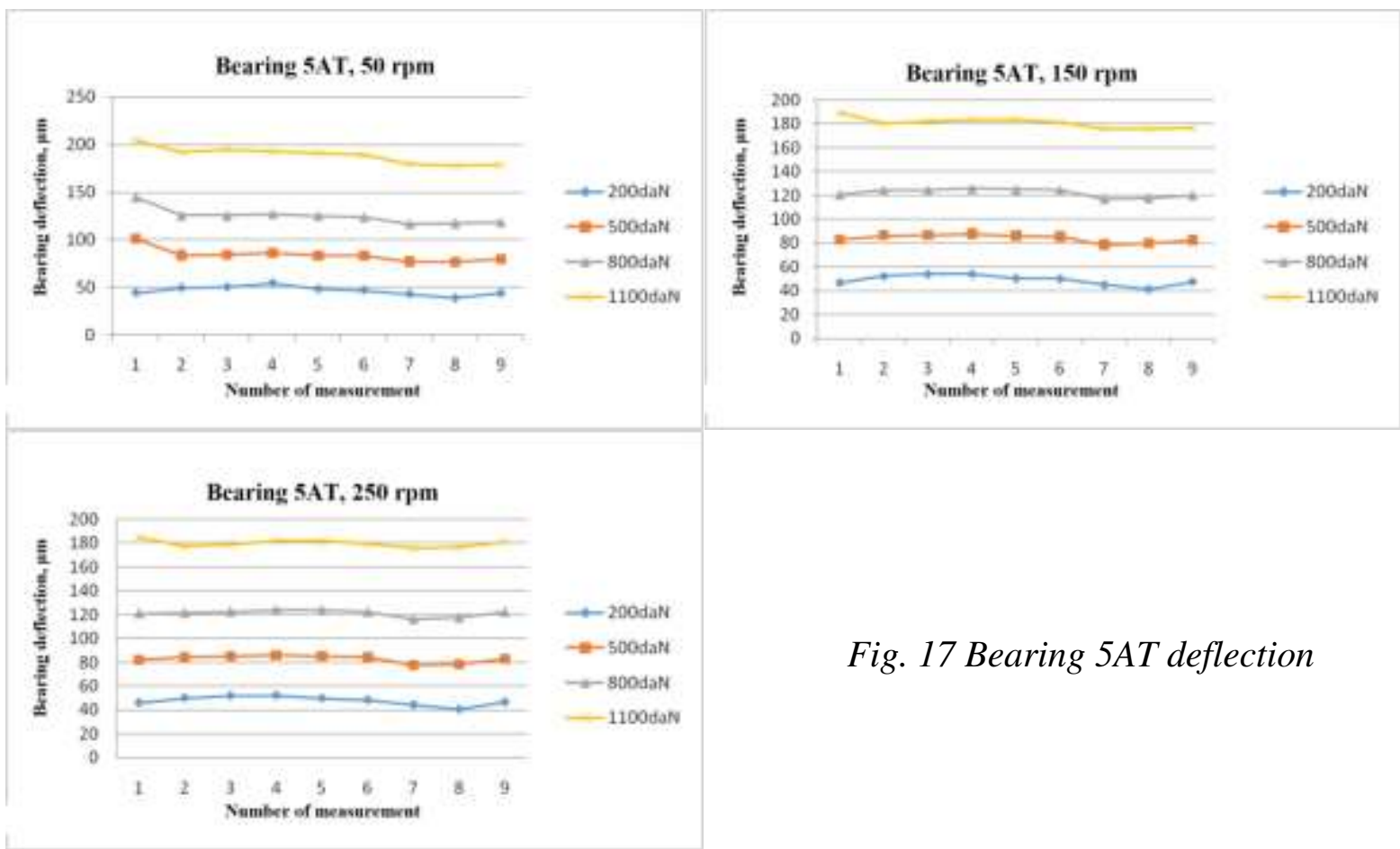

Fig. 17 Bearing 5AT deflection 
The analysis of the obtained data on the assembly height measurement allows to draw the following conclusions:

- The results of the mounting height measurements are highly repeatable. This can be seen both in the direct measurement reports and in the general overview.

- The obtained results are distributed in a rational manner. The increase in the displacement of one ring relative to the other is proportional to the force increase. A certain exception is the change in dimension with a load of $1100 \mathrm{daN}$, resulting in a significantly larger displacement than in the previous three cases. This consistency is maintained for each subsequent measurement, which suggests that it is a natural phenomenon for this type of rolling bearings.

The slight variation in the result, which is best seen on the example of bearing $2 \mathrm{O}$ measurements, is random and is a natural phenomenon that occur in test devices. It can be assumed that the spread obtained for the bearing $2 \mathrm{O}$ is characteristic of the constructed mounting height measuring system of the test device.

- Higher scatter for the remaining bearings may be associated with the inadequate sensor zeroing procedure. This is evidenced by the consistent excessive or insufficient values obtained for the one measurement number (for all 12 combinations of force and rotational speed).

\section{Conclusions and recommendations}

The device is ready to perform the tasks for which it was designed. The adopted test parameters are achievable. The performed tests showed that the obtained accuracy of the performed measurements meets the requirements of the assumptions adopted at the test rig designing stage.

The test rig is ready for operation. Before starting, a number of measures should be taken to minimize the possibility of making mistakes in the test execution technique and the analysis of the results and their evaluation. The measures include:

- additional calibration of measuring sensors,

- conducting a cycle of tests aimed at optimizing the methodology of sensors zeroing before starting the measurement process,

- carrying out tests using various lubricants in order to optimize their selection for the bearing operating conditions assumed for the test, 
- checking whether the function for specific rotational speeds is consistently reproduced at various loads, if the test cycle is performed without the initial dismantling of the bearing,

- performing tests on a series of bearings of different sizes and on a larger number of samples,

- checking the possibility of measuring the frictional moment on a bearing with the outer ring slidably mounted.

Finally, it is worth paying attention to the level of values obtained in the test. The torque values obtained empirically are consistently greater than those obtained through calculation. This is obviously due to not taking into account all the factors affecting the bearing frictional moment, such as cage friction, the geometric structure of the mating surfaces, the dimensional and shape accuracy of the bearing elements or even the lubricant purity.

Therefore, it is recommended that both the scientific and the industrial teams, in addition to measuring the frictional moment, conducted also extensive experimental works aimed at determining as many factors as possible influencing the result of the frictional moment measurement, simultaneously being aware that some of these factors will be caused by the measuring device itself, which is very often overlooked.

\section{Declarations}

\section{7a. Funding}

No funding was received for conducting this study.

\section{7b. Conflicts of interest/Competing interests}

The authors declare they have no financial interests.

\section{7c. Availability of data and material}

All posted data is available and verifiable.

\section{7d. Code availability}

Not applicable. 


\section{7e. Ethics approval}

Not applicable.

\section{7f. Consent to participate.}

Not applicable.

\section{7g. Consent for publication.}

All authors and their affiliations agree to publish the manuscript.

\section{7h. Authors' contributions.}

Each of the authors mentioned had a measurable impact on the creation of this manuscript.

\section{References}

[1] Zhang Ch., Gu L., Mao Y., Wang L.: Modeling the frictional torque of a dry-lubricated tapered roller bearing considering the roller skewing. Friction 7(6), pp. 551-563 (2019).

[2] Vale JL, Silva CH: Kinetic friction coefficient modeling and uncertainty measurement evaluation for a journal bearing test apparatus. Measurement 154 (2020).

[3] Adamczak S., Domagalski R. Sender E.: Friction torque in rolling bearings - methods and test facilities. Tribology 6/2011, pp. 19-28 (2011).

[4] Geonea I., Dumitru N., Dumitru I.: Experimental and theoretical study of friction torque from radial ball bearings. Materials Science and Engineering 252 (2017).

[5] Bălan MR, Houpert L., Tufescu A., Olaru DM.: Rolling Friction Torque in Ball-Race Contacts Operating in Mixed Lubrication Conditions. Lubricants 3, pp. 222-243 (2015).

[6] Cousseau T. et al.: Experimental measuring procedure for the friction torque in rolling bearings. Lubrication Science 22, pp. 133-147 (2010).

[7] Cousseau T., Graça B., Campos A., Seabra J: Friction torque in grease lubricated thrust ball bearings. Tribology International 44 (5), pp. 523-531 (2011).

[8] Han CF et al.: Uses of empirical mode decomposition and multi-entropy techniques to establish the correlations among vibrations, friction coefficients and component wear of ball-bearing-like specimens. Measurement 150 (2020).

[9] Summer F., Grün F., Offenbecher M., Taylor S.: Challenges of friction reduction of engine plain bearings - Tackling the problem with novel bearing materials. Tribology International 131, pp. 238-250 (2019). 
[10] Kwak W., Lee J., Lee Y.B.: Theoretical and experimental approach to ball bearing frictional characteristics compared with cryogenic friction model and dry friction model. Mechanical Systems and Signal Processing 124, pp. 424-438 (2019).

[11] Qiu C. et al.: An approximate estimation approach of fault size for spalled ball bearing in induction motor by tracking multiple vibration frequencies in current. Sensors 20(6) (2020).

[12] Li S., Li Y., ChoiS. W. Sarlioglu B.: High Speed Electric Machines - Challenges and Design Considerations. IEEE Transactions on Transportation Electrification, 2(1), pp. 2-13, (2016)

[13] Rabréau C. et al.: Influence of bearing kinematics hypotheses on ball bearing heat generation, Procedia CIRP 77, pp. 622-625 (2018).

[14] Dykas B.: Factors influencing the performance of foil gas thrust bearings for oil-free turbomachinery applications. Doctoral thesis, Department of Mechanical and Aerospace Engineering, Case Western Reserve University (2006).

[15] Marques P., Martins R., Seabra J.: Experimental measurement of rolling bearing torque loss in a modified Four-Ball machine: An improved setup. Lubrication Science 32 (5), pp. 245-259 (2020).

[16] Paleu V., Cretu S., Drăgan B., Bălan R.: Test Rig For Friction Torque Measurement in Rolling Bearings. The Durham University journal. University of Durham VIII(1), pp. 85-91 (2004).

[17] Fiedler S., Kiekbusch T., Sauer B.: Investigation of inner contact and friction conditions of a spherical roller bearing using multi-body simulation. Periodica Polytechnica, Mechanical Engineering 55(2), pp.79-84 (2011).

[18] Li X. et al.: A Novel Bearing Fault Diagnosis Method Based on LMD and Wavelet Packet Energy Entropy. International Journal of Emerging Electric Power Systems 18(5), pp. 1-16 (2017).

[19] Dindar A., Akkök M., Caliskan M.: Experimental determination and analytical model of friction torque of a double row roller slewing bearing. Journal of Tribology 139(2) (2016). 